\title{
Plasma level of advanced oxidation protein products as a novel biomarker of acute lung injury following cardiac surgery
}

\author{
Songlin $\mathrm{Du}^{1 \dagger}$, Jun $\mathrm{Ai}^{2 \dagger}$, Xiangzhen Zeng ${ }^{3}$, Jun Wan ${ }^{1}, \mathrm{Xu} \mathrm{Wu}^{1}$ and Jianxing $\mathrm{He}^{1,4,5^{*}}$
}

\begin{abstract}
This study was designed to test the hypothesis that whether the plasma level of advanced oxidant protein products (AOPPS) would be useful for the clinical diagnosis of acute lung injury (ALI) following cardiac surgery with the technique of cardiopulmonary bypass (CPB). In this prospective study, seventy consecutive adults undergoing open heart surgery with CPB were included and assigned into the ALI $(n=18)$ and non-ALI $(n=52)$ groups according to the American-European Consensus Criteria. Plasma concentrations of AOPPs were measured at baseline, postoperative $1 \mathrm{~h}, 12 \mathrm{~h}, 24 \mathrm{~h}$, and $48 \mathrm{~h}$. Eighteen patients (25.7\%) developed ALI after surgery. The plasma levels of AOPPs in the ALI group were significantly increased and remained considerably higher at all time points after operation (all $P<0.05$ ). Multivariate logistic regression analysis revealed that the plasma level of AOPPs at $1 \mathrm{~h}$ after operation was an independent predictor for the diagnosis of ALI (OR 1.164; $95 \% \mathrm{Cl} 1.068-1.269 ; P=0.001)$. Plasma level of AOPPs could serve as an early biomarker of the incidence of ALI in adult patients who underwent open cardiac surgery with the technique of CPB.
\end{abstract}

Keywords: Acute lung injury, Cardiopulmonary bypass, Advanced oxidation protein products, Oxidative stress, Biomarker

\section{Background}

Acute lung injury (ALI) is a common complication in patients undergoing cardiac surgery with the technique of cardiopulmonary bypass $(\mathrm{CPB})$ with a high morbidity and mortality (Vlaar et al. 2011; Apostolakis et al. 2010; Koch et al. 2009; Stephens et al. 2013). If ALI evolved into acute respiratory distress syndrome (ARDS), the mortality of ALI may be as high as $80 \%$ (Koch et al. 2009; Stephens et al. 2013; Ng et al. 2002). ALI complication could prolong the length of intensive care unit (ICU) and hospital stay, and raise treatment expenses (Kogan et al. 2014). In spite of widespread studies, no effective therapy can accelerate the recovery. Predicting ALI/ARDS would

\footnotetext{
*Correspondence: ProfHejx@163.com

†Songlin Du and Jun Ai are first co-authors

${ }^{1}$ Department of Thoracic and Cardiovascular Surgery, Nanfang Hospital of Southern Medical University, 1838 North Guangzhou Avenue,

Guangzhou 510515, China

Full list of author information is available at the end of the article
}

be extremely valuable for making clinical decisions and guiding subsequent research.

The incidence of ALI/ARDS following CPB was associated with multiple overlapping biological pathways, cell and tissue injury, which may generate a large quantity of potential biomarkers (Levitt et al. 2009). Ideal biomarkers could be used to identify pivotal biological pathways underlying the pathogenesis of ALI/ARDS and played a vital role in the early diagnosis of this disorder. Unfortunately, biomarkers remained largely a research tool over the past two decades. Previous studies have demonstrated that oxidative stress contributes to the progression of ALI/ARDS induced by different causes, such as CPB, sepsis, trauma and multiple transfusions, etc. (Uchida et al.2006; Calfee et al. 2008; Chow et al. 2003). Pulmonary oxidant production can lead to the incidence of ALI and occasionally progressive lung injury (Chow et al. 2003; Ward 2010). One of the pivotal mechanisms of ALI/ARDS after CPB is oxidative injury to the lung mediated by reactive oxygen species (ROS)

\section{Springer}

(c) 2016 Du et al. This article is distributed under the terms of the Creative Commons Attribution 4.0 International License (http:// creativecommons.org/licenses/by/4.0/, which permits unrestricted use, distribution, and reproduction in any medium, provided you give appropriate credit to the original author(s) and the source, provide a link to the Creative Commons license, and indicate if changes were made. 
including superoxide anion radical $\left(\mathrm{O}_{2}{ }^{-}\right)$, hydrogen peroxide $\left(\mathrm{H}_{2} \mathrm{O}_{2}\right)$, hydroxyl radical $\left(\mathrm{OH}^{-}\right)$, and hypochlorous acid (HOCl) (Ward 2010). ROS can lead to cell injury via protein oxidation that alters protein activity, causing release of proteases and inactivation of antioxidant and anti-protease enzymes (Chow et al. 2003; Ward 2010; Tuinman et al. 2013). Accumulated experimental evidence supported that $\mathrm{HOCl}$ may lead to irreversible lung damage and even fibrosis (Chow et al. 2003; Ward 2010; Tuinman et al. 2013; Johnson and Koval 2009). Advanced oxidation protein products (AOPPs) are generated as a result of the reaction between plasma proteins and chlorinated oxidants, such as chloramines and $\mathrm{HOCl}(\mathrm{Wu}$ et al. 2015). More importantly, AOPPs are utilized not only as a biomarker of oxidative stress but also a mediator of inflammation, which potentially reflects multiple aspects of the pathogenesis and pathophysiology of ALI/ ARDS following CPB (Liang et al. 2012; Gangemi et al. 2015; Bochi et al. 2014). These modified molecules may efficiently monitor the progression and outcome of ALI/ ARDS induced by CPB. Hence, we hypothesized that AOPPs would be useful for biological confirmation of the clinical diagnosis of ALI/ARDS following cardiac surgery with $\mathrm{CPB}$.

The aim of this prospective study was to examine the plasma levels of AOPPs in patients with ALI following cardiac surgery and explore whether these molecules serve as useful markers in predicting the incidence of ALI in these patients.

\section{Methods}

\section{Study population}

This prospective study was performed in Nanfang Hospital affiliated to Southern Medical University, China. Inclusion criteria should be met if seventy patients aged $>18$ years undergoing cardiac surgery with $\mathrm{CPB}$ at our department between January and May 2014 were included in this clinical trial. The study protocols were approved by the Ethics Committee of Nanfang Hospital of Southern Medical University. Informed consents were obtained from all participants included in this study. Exclusion criteria: Patients were excluded if they were with abnormal liver or renal function, pulmonary inflammation before surgery, pulmonary edema due to cardiac dysfunction or died from cardiac dysfunction.

\section{Data collection}

Demographic data, preoperative risk factors, and perioperative surgical and anesthetic management data including the patient's gender, age, body mass index (BMI), pulse oximetry saturation $\left(\mathrm{SpO}_{2}\right)$, CPB time and Clamp time and arterial partial pressure of oxygen to fraction of inspired oxygen $\left(\mathrm{PaO}_{2} / \mathrm{FiO}_{2}\right)$, length of surgery intensive care unit (SICU) stay and hospital stay were collected. A pulmonary artery catheter was inserted into all patients before operation. $\mathrm{CPB}$ was performed under mild to moderate hypothermia $\left(28-34{ }^{\circ} \mathrm{C}\right)$ in all patients. Chest radiograph was routinely taken before surgery and every day after surgery. Echocardiography was performed routinely to evaluate postoperative cardiac function at any time if necessary. Left ventricular function was evaluated by the index of ejection fraction (EF).

\section{Main definitions}

Patients were categorized into the ALI $(\mathrm{n}=18)$ and nonALI groups $(\mathrm{n}=52)$ according to American-European Consensus Conference (AECC) definition (Bernard et al. 1994). ALI was defined as follows: oxygenation: $\mathrm{PaO}_{2} /$ $\mathrm{FiO}_{2}<300 \mathrm{mmHg}$ (regardless of positive end-expiratory pressure); chest radiograph: bilateral infiltrates seen on frontal chest radiograph, pulmonary artery occlusion pressure: $<18 \mathrm{mmHg}$, the absence of cardiogenic pulmonary edema (CPE). CPE was identified when the pulmonary arterial occlusion pressure was $>18 \mathrm{mmHg}$ or by the presence of central venous pressure $>14 \mathrm{mmHg}$ and left ventricular $\mathrm{EF}<45 \%$.

\section{Determination of plasma AOPPs}

For each patient, serial plasma samples were obtained at the baseline level, 1, 12, 24, and $48 \mathrm{~h}$ after operation and stored at $-80^{\circ} \mathrm{C}$. In previous reports, plasma AOPPs were determined using the semi-automated method (Lentini et al. 2010). In test wells, a portion of $200 \mu \mathrm{L}$ of plasma was diluted to a ratio of 1:5 in phosphate-buffered saline (PBS), placed into a 96-well microtiter plate, and supplemented with $20 \mu \mathrm{L}$ of acetic acid. In standard wells, $10 \mu \mathrm{L}$ of potassium iodide was added to $200 \mu \mathrm{L}$ of chloramine-T solution $(0-100 \mu \mathrm{mol} / \mathrm{L})$ and followed by $20 \mu \mathrm{L}$ of acetic acid. The absorbance value was immediately measured at a wavelength of $340 \mathrm{~nm}$. The concentration of AOPPs was expressed in unit of $\mu \mathrm{mol} / \mathrm{L}$ of chloramine$T$ equivalents. Laboratory operators were blinded to the ALI patients, and relevant investigators involved in the interpretation of ALI were blinded to AOPPs levels.

\section{Statistical analysis}

All statistical analyses were performed with SPSS 19.0 for Windows (SPSS Inc., Chicago, IL, USA). Continuous data were analyzed for normal distribution with onesample Kolmogorov-Smirnov test. Normally-distributed data were further analyzed using unpaired student's $t$ test. Abnormally-distributed data were analyzed using Mann-Whitney $U$ test. $\chi^{2}$ test was employed to compare categorical data as appropriate. A multivariate analysis of variance procedure (MANOVA) was used to assess whether a significant difference existed in the assessment 
of AOPPs levels between two groups. Receiver operating characteristic curve (ROC) was computed, and area under the curve (AUC) was calculated to evaluate the significance of these biomarkers in diagnosing ALI. Risk factors related to the development of ALI, such as age, sex, body mass index (BMI), CPB time or clamp time, were introduced into the univariate analysis. Multivariate stepwise forward logistic regression analysis was then performed for statistically significant univariate predictors to determine the independent risk factor for ALI after CPB. $P<0.05$ was accepted as statistically significant.

\section{Results}

\section{Demographic characteristics}

A total of 70 patients fulfilled the inclusion criteria. Among them, 18 (25.7 \%) developed ALI. Demographic and perioperative characteristics of all participants are illustrated in Table 1. Age, BMI, smoking, diabetes mellitus, cardiothoracic ratio, LVEF, operation type, CPB time, clamp time and preoperative AOPPs did not significantly differ between two groups. However, the incidence of COPD, hypertension and the proportion of male were significantly increased in patients with ALI compared with non-ALI counterparts. In addition, the duration of SICU stay and hospital stay were significantly prolonged in the ALI group compared with those in the non-ALI group. The first significant decline of $\mathrm{PaO}_{2}: \mathrm{FiO}_{2}$ ratio occurred at $1 \mathrm{~h}$ after operation (Fig. 1). The ratio of $\mathrm{PaO}_{2}: \mathrm{FiO}_{2}$ at postoperative 12,24 and $48 \mathrm{~h}$ in the ALI group was significantly lower than that in the non-ALI group, as illustrated in Table 2 and Fig. 1. Interestingly, $\mathrm{PaO}_{2}: \mathrm{FiO}_{2}$ ratio in the ALI group decreased to lowered than $300(270 \pm 43.1)$ at $24 \mathrm{~h}$ after operation.

\section{Plasma AOPPs}

For all patients, postoperative plasma levels of AOPPs were increased compared to the baseline level (Fig. 2). Plasma concentration of AOPPs was shown in Table 3. The levels of plasma AOPPs were first significantly increased at $1 \mathrm{~h}$ after operation and declined at postoperative $12 \mathrm{~h}$ in all patients. The levels of plasma AOPPs in the ALI group were significantly higher than those in the non-ALI group at 1, 12, 24 and $48 \mathrm{~h}$ after operation. Plasma level of AOPPs in non-ALI patients decreased to the baseline level, whereas those in ALI counterparts remained higher than the baseline level at $24 \mathrm{~h}$ after

Table 1 Demographic and clinical characteristics between ALI and non-ALI patients

\begin{tabular}{|c|c|c|c|c|}
\hline & ALL $(n=70)$ & $A L I(n=18)$ & Non-ALI $(n=52)$ & $P$ value \\
\hline \multicolumn{5}{|l|}{ Basic parameters } \\
\hline Male (n) & 37 & 12 & 25 & $<0.001$ \\
\hline Age (years) & $47.9 \pm 11.3$ & $57.7 \pm 11.6$ & $46.6 \pm 11.4$ & 0.105 \\
\hline Body mass index & $21.6 \pm 3.60$ & $22.9 \pm 2.90$ & $21.1 \pm 3.8$ & 0.081 \\
\hline Smoking (n) & 15 & 6 & 9 & 0.153 \\
\hline $\operatorname{COPD}(\mathrm{n})$ & 7 & 5 & 2 & 0.01 \\
\hline Hypertension (n) & 9 & 6 & 3 & 0.007 \\
\hline Diabetes mellitus (n) & 4 & 3 & 1 & 0.05 \\
\hline Cardiothoracic ratio & $0.61 \pm 0.09$ & $0.63 \pm 0.08$ & $0.61 \pm 0.1$ & 0.415 \\
\hline $\operatorname{LVEF(\% )}$ & $59.9 \pm 7.0$ & $57.9 \pm 6.5$ & $60.6 \pm 7.1$ & 0.154 \\
\hline \multicolumn{5}{|l|}{ Intraoperative parameters } \\
\hline Type of surgery & & & & 0.223 \\
\hline Coronary artery disease (\%) & $11(15.7 \%)$ & $5(27.8 \%)$ & $6(11.5 \%)$ & \\
\hline Valve heart disease (\%) & $52(74.3 \%)$ & $12(66.7 \%)$ & $40(77.0 \%)$ & \\
\hline Congenital heart disease (\%) & $7(10 \%)$ & $1(5.5 \%)$ & $6(11.5 \%)$ & \\
\hline CPB time (min) & $106.4 \pm 37.8$ & $116.3 \pm 31.5$ & $102.9 \pm 39.4$ & 0.198 \\
\hline Clamp time (min) & $68.5 \pm 30.8$ & $73.3 \pm 24$ & $66.9 \pm 32.9$ & 0.452 \\
\hline \multicolumn{5}{|l|}{ Peri-operative risk factors } \\
\hline Preoperative AOPPs $(\mu \mathrm{mol} / \mathrm{L})$ & $46.0 \pm 10.5$ & $47.1 \pm 7.9$ & $44.8 \pm 10.8$ & 0.394 \\
\hline SICU stay (days) & $3(2,5)$ & $7.3 \pm 4.4$ & $3(2,3)$ & $<0.001$ \\
\hline Hospital stay (days) & $17.3 \pm 5.9$ & $24.4 \pm 5.8$ & $14.8 \pm 3.4$ & $<0.001$ \\
\hline
\end{tabular}

Data are presented as number of patients (\%), mean \pm SD, or counts, as appropriate

$A L I$ acute lung injury, COPD chronic obstructive pulmonary disease, $L V E F$ left ventricular ejection fraction, $C P B$ cardiopulmonary bypass, SICU surgery intensive care unit 


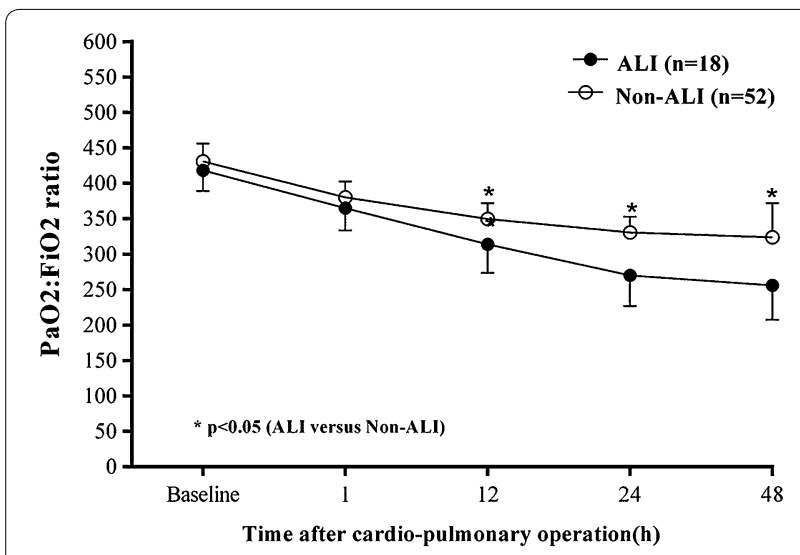

Fig. 1 The ratio of $\mathrm{PaO}_{2}$ and $\mathrm{FiO}_{2}$ at baseline level and different time points after operation. Error bar are SD

operation (Table 3; Fig. 2). In the ALI group, the level of AOPPs peaked at postoperative $1 \mathrm{~h}$, dramatically decreased at $12 \mathrm{~h}$ after operation, and began to increase at postoperative $24 \mathrm{~h}$ after operation.

\section{Plasma AOPPs as a predictor for ALI progression}

Univariate analysis demonstrated that plasma level of AOPPs at $1 \mathrm{~h}$ after operation (OR 1.148; $95 \%$ CI 1.0651.237; $P<0.001$ ), age (OR 1.103; $95 \%$ CI 1.041-1.168; $P=0.001$ ), COPD (OR 9.615; $95 \%$ CI 1.671-55.314; $P=0.011$ ), hypertension (OR 8.167; $95 \%$ CI 1.781$37.449 ; P=0.007)$ were significantly associated with increased risk of ALI.

After adjustment for age, diabetes mellitus and hypertension by multivariable logistic analysis, plasma level of AOPPs at $1 \mathrm{~h}$ after operation (OR 1.1674; $95 \% \mathrm{CI}$ 1.068-1.269; $P=0.001$ ) and COPD (OR 28.706; $95 \% \mathrm{CI}$ 1.770-465.640; $P=0.018$ ) were highly associated with increased risk of ALI (Table 4). As Fig. 3 illustrated, the area under the ROC curve of plasma level of AOPPs at postoperative $1 \mathrm{~h}$ was calculated as 0.875 , indicating the clinical significance of plasma level of AOPPs at $1 \mathrm{~h}$ after operation in the diagnosis of ALI. Derived sensitivity, specificity, and predictive cutoff value of plasma level of AOPPs at postoperative $1 \mathrm{~h}$ are listed in Table 5. Plasma level of AOPPs at $1 \mathrm{~h}$ after operation yielded the

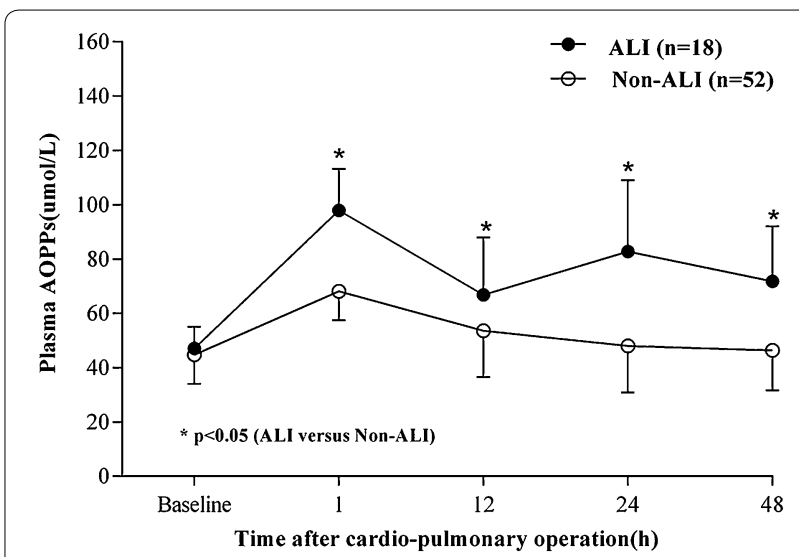

Fig. 2 Mean plasma concentration of AOPPs at baseline level and different time points after operation. Error bar are SD

highest sensitivity and specificity at the cutoff value of $81.89 \mu \mathrm{mol} / \mathrm{L}$ (Table 5).

\section{Discussion}

It is well known that the production of oxidants within the lung can lead to the incidence of ALI, reversible or even irreversible progressive lung injury (Ward 2010; Johnson and Koval 2009). Reversibility occurs when the stimulus of intrapulmonary oxidants overcomes the limit of natural antioxidant enzymes in the lung. Stressinduced alterations in the conformation or structure of proteins are capable of inducing protein dysfunction or inhibiting protein degradation (Chow et al. 2003). Modified proteins can subsequently induce cellular dysfunctions and tissue damage. Under such conditions, the regenerative capacity of the lung is overwhelmed, which promotes the development of ALI/ARDS (Apostolakis et al. 2010). AOPPs are relatively stable molecules that can be measured by fast and inexpensive techniques, which makes AOPPs as suitable biomarkers for monitoring oxidative stress (Bochi et al. 2014). Previous studies provided evidence that the levels of oxidative stress in patients receiving off-pump operations were significantly lower compared with those in the counterparts undergoing $C P B$ surgery (Matata et al. 2000). In this investigation, plasma AOPPs levels were elevated after cardiac surgery with $\mathrm{CPB}$ and directly associated with

Table 2 The ratio of $\mathrm{PaO}_{2}$ and $\mathrm{FiO}_{2}$ at baseline level and different time points after operation

\begin{tabular}{|c|c|c|c|c|c|}
\hline $\mathrm{PaO}_{2}: \mathrm{FiO}_{2}$ ratio & Before operation & $1 \mathrm{~h}$ after operation & $12 \mathrm{~h}$ after operation & $24 \mathrm{~h}$ after operation & $48 \mathrm{~h}$ after operation \\
\hline $\mathrm{ALI}$ & $418 \pm 29.5$ & $365 \pm 31.6$ & $314 \pm 40.2^{a}$ & $270 \pm 43.1^{a}$ & $256 \pm 48.2^{a}$ \\
\hline Non-ALI & $431 \pm 25.4$ & $380 \pm 21.9$ & $350 \pm 22.0$ & $331 \pm 22.0$ & $324 \pm 47.7$ \\
\hline
\end{tabular}

Data were shown as mean \pm SD

$A L /$ acute lung injury

a $\mathrm{P}<0.05$ versus Non-ALI group at the same time point 
Table 3 Plasma AOPPs ( $\mu \mathrm{mol} / \mathrm{L}$ ) at baseline level and different time points after operation

\begin{tabular}{llllll}
\hline AOPPs & Before operation & $\mathbf{1} \mathbf{h}$ after operation & $\mathbf{1 2} \mathbf{h}$ after operation & 24 $\mathbf{h}$ after operation & 48 $\mathbf{h}$ after operation \\
\hline ALI & $55.7 \pm 11.3$ & $97.9 \pm 15.3^{\mathrm{a}}$ & $66.8 \pm 21.2^{\mathrm{a}}$ & $82.8 \pm 26.2^{\mathrm{a}}$ & $71.8 \pm 20.2^{\mathrm{a}}$ \\
Non-ALI & $44.8 \pm 10.8$ & $68.2 \pm 10.7$ & $53.6 \pm 17.1$ & $48.0 \pm 17.1$ & $46.4 \pm 14.7$ \\
\hline
\end{tabular}

Data were shown as mean \pm SD

$A L /$ acute lung injury

${ }^{\text {a }} \mathrm{P}<0.05$ versus Non-ALI group at the same time point

Table 4 Univariate and multivariate analysis of plasma AOPPs after operation for prediction of ALI

\begin{tabular}{|c|c|c|c|c|}
\hline & \multicolumn{2}{|l|}{ Univariate } & \multicolumn{2}{|l|}{ Multivariate } \\
\hline & OR $(95 \% \mathrm{Cl})$ & $\mathbf{P}$ & OR $(95 \% \mathrm{Cl})$ & $\mathbf{P}$ \\
\hline AOPPs $1 \mathrm{~h}$ after operation & $1.148(1.065,1.237)$ & $<0.001$ & $1.164(1.068,1.269)$ & 0.001 \\
\hline Age & $1.103(1.041,1.168)$ & 0.001 & $1.054(0.984,1.129)$ & 0.130 \\
\hline COPD & $9.615(1.671,55.314)$ & 0.011 & $28.706(1.770,465.64)$ & 0.018 \\
\hline Diabetes mellitus & $10.20(0.987,105.38)$ & 0.051 & $1.485(0.085,26.040)$ & 0.787 \\
\hline Hypertension & $8.167(1.781,37.449)$ & 0.007 & $0.665(0.059,7.501)$ & 0.741 \\
\hline BMI & $1.147(0.984,1.336)$ & 0.079 & $0.998(0.758,1.313)$ & 0.989 \\
\hline Systolic BP & $1.049(1.001,1.099)$ & 0.052 & $1.061(0.982,1.147)$ & 0.133 \\
\hline
\end{tabular}

$\mathrm{P}<0.10$ in the univariate analysis were candidates for the multivariable logistic analysis (including variables: AOPPs $1 \mathrm{~h}$ after operation, Age, COPD, diabetes mellitus, hypertension, BMI and systolic BP)

$A L I$ acute lung injury, Systolic BP systolic blood pressure

the occurrence of ALI and a poor clinical outcome, validating the hypothesis that plasma AOPPs is a reliable biomarker of the risk of ALI following cardiac surgery. Furthermore, the AOPPs levels in the ALI group were significantly higher than those in the non-ALI

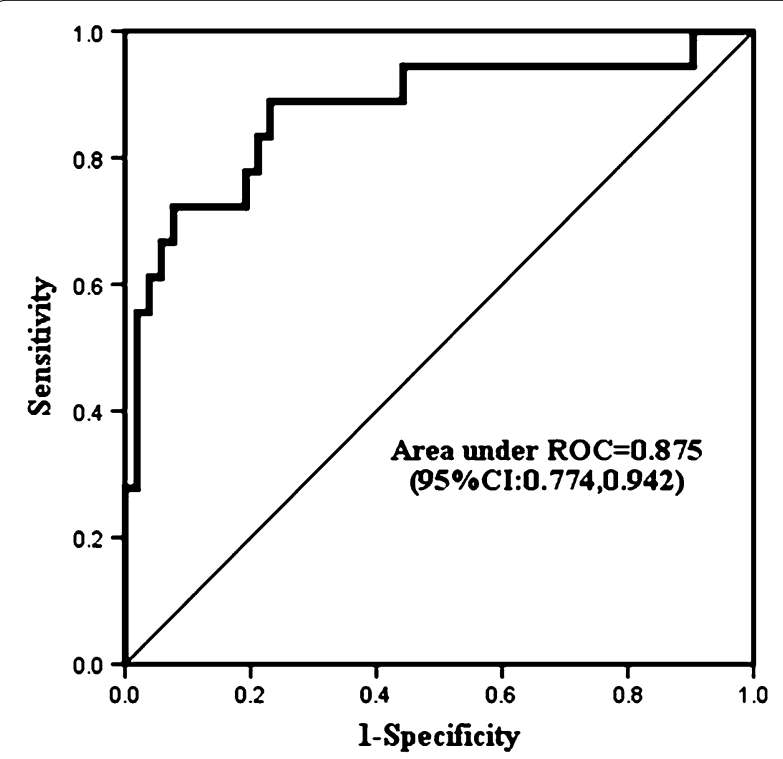

Fig. 3 ROC curve analysis of plasma levels of AOPPs measured at $1 \mathrm{~h}$ after operation. The area under the curve was 0.875 (95 \% Cl 0.774, 0.942) group at 1, 12, 24 and $48 \mathrm{~h}$ after operation, suggesting that plasma AOPPs levels may serve as a reliable predictor for the progression of ALI following CPB in adult patients.

Dynamic detection of the plasma levels of AOPPs was performed at 1, 12, 24 and $48 \mathrm{~h}$. The plasma levels of AOPPs in all patients peaked quickly at $1 \mathrm{~h}$ after operation, and then dropped to the baseline level at postoperative $12 \mathrm{~h}$. At $24 \mathrm{~h}$ after surgery, the levels of plasma AOPPs in the ALI patients increased again and were maintained significantly higher compared with those in the non-ALI counterparts. The elevation in the plasma AOPPs levels may reflect the duration of excessive oxidative stress. Meanwhile, $\mathrm{PaO}_{2}: \mathrm{FiO}_{2}$ ratio decreased at $12 \mathrm{~h}$ after operation, and then declined to $<300$, which was considered as the diagnostic level of ALI at postoperative $24 \mathrm{~h}$. Thus, plasma levels of AOPPs at $1 \mathrm{~h}$ after operation served as the first predictor of the incidence of ALI. The cutoff value of AOPPs was calculated as $81.89 \mu \mathrm{mol} / \mathrm{L}$. There is growing evidence that increased oxidative stress ultimately induces endogenous defense mechanisms and inhibitory responses through negatively modulating cellular signaling pathways (Ward 2010). Understanding the dynamic interaction between intrapulmonary oxidant production and engagement of antioxidant defenses provides supplementary information relevant to the incidence of ALI/ARDS following CPB. 
Table 5 Performance of plasma AOPPs $1 \mathrm{~h}$ after operation ( $\mu \mathrm{mol} / \mathrm{L}$ ) for diagnosis of ALI

\begin{tabular}{|c|c|c|c|c|c|}
\hline & \multirow{2}{*}{$\begin{array}{l}\text { Area under ROC curve } \\
(95 \% \mathrm{Cl})\end{array}$} & \multicolumn{4}{|c|}{ At cutoff value of $81.89(\mu \mathrm{mol} / \mathrm{L})$} \\
\hline & & Sensitivity $(95 \% \mathrm{Cl})$ & Specificity $(95 \% \mathrm{Cl})$ & PPV $(95 \% \mathrm{CI})$ & NPV (95 \% Cl) \\
\hline $\begin{array}{l}\text { AOPPs } 1 \mathrm{~h} \text { after operation } \\
(\mu \mathrm{mol} / \mathrm{L})\end{array}$ & $0.875(0.774,0.942)$ & $0.722(0.465,0.903)$ & $0.923(0.815,0.979)$ & $0.765(0.492,0.935)$ & $0.906(0.793,0.969)$ \\
\hline
\end{tabular}

Several potential limitations have to be acknowledged in our study. First, the results were obtained based on a relatively small sample size in one single center. Hence, a larger-cohort study is needed to verify these results. Second, traditional inflammatory cytokines were not quantitatively measured in this study. However, none of them was a specific biomarker for the occurrence of ALI post-CPB. Third, it is difficult to conclude that whether increased plasma levels of AOPPs are the cause of ALI or the consequence of major surgery which subsequently leads to ALI. However, due to the fact that perioperative characteristics did not significantly differ between the ALI and non-ALI groups, we believe that elevated plasma levels of AOPPs serve as a marker for the incidence after $\mathrm{CPB}$. Specifically-designed study is required to further address this issue.

\section{Conclusions}

In conclusion, this is the first study identifying the potential role of AOPPs involved with the incidence of ALI following open cardiac surgery with the technique of CPB. We found that plasma levels of AOPPs could be used as an early biomarker of the occurrence of ALI after cardiac surgery with $\mathrm{CPB}$ in adult patients. The plasma levels of AOPPs are associated with lung function and clinical outcome after CPB. The precise role of AOPPs in the clinical presentations and progression of ALI following cardiac surgery remain to be elucidated.

\begin{abstract}
Abbreviations
AOPPs: advanced oxidant protein products; ALI: acute lung injury; CPB: cardiopulmonary bypass; ARDS: acute respiratory distress syndrome; ICU: intensive care unit; $\mathrm{ROS}$ : reactive oxygen species; $\mathrm{HOCl}$ : hypochlorous acid; BMl: body mass index; $\mathrm{SpO}_{2}$ : pulse oximetry saturation; $\mathrm{PaO}_{2} / \mathrm{FiO}_{2}$ : arterial partial pressure of oxygen to fraction of inspired oxygen; SICU: surgery intensive care unit; LVEF: left ventricular ejection fraction; COPD: chronic obstructive pulmonary disease; PBS: phosphate-buffered saline; ROC: receiver operating characteristic curve; AUC: area under the curve.
\end{abstract}

\footnotetext{
Authors' contributions

$\mathrm{JH}$ mainly contributed to the present paper, conceptualized and designed the paper, and drafted the manuscript. SD carried out operations, samples detection, and drafted the manuscript. JA and JW helped to carry out operations and draft the manuscript. XW participated in the blood sample collection. XZ performed the statistical analysis. All authors read and approved the final manuscript.
}

\section{Author details}

${ }^{1}$ Department of Thoracic and Cardiovascular Surgery, Nanfang Hospital of Southern Medical University, 1838 North Guangzhou Avenue, Guangzhou 510515, China. ${ }^{2}$ Division of Nephrology, Nanfang Hospital of Southern Medical University, Guangzhou 510515, China. ${ }^{3}$ Division of Nephrology, Loudi City Central Hospital, Loudi 417099, China. ${ }^{4}$ State Key Laboratory of Respiratory Disease, Guangzhou 510120, China. ${ }^{5}$ National Clinical Research Center for Respiratory Disease, Guangzhou 510120, China.

\section{Acknowledgements}

This work was funded by the Scientific Research Foundation of Southern Medical University, China (Grant No. PN2014N044) for Dr. Songlin Du and the Grant of Presidential Foundation of Nanfang hospital, China (Grant No. 2012C018) for Dr. Jun Ai. The authors thank our nurses, Shuang Wen, QingMiao Guo, Qiuhui Wu, and Mei Li, for their assistance, and our patients for their participation.

\section{Competing interests}

The authors declare that they have no competing interests.

Received: 16 December 2015 Accepted: 17 February 2016 Published online: 29 February 2016

\section{References}

Apostolakis E, Filos KS, Koletsis E, Dougenis D (2010) Lung dysfunction following cardiopulmonary bypass. J Card Surg 25:47-55

Bernard GR, Artigas A, Brigham KL, Carlet J, Falke K, Hudson L, Lamy M, Legall JR, Morris A, Spragg R (1994) The American-European Consensus Conference on ARDS. Definitions, mechanisms, relevant outcomes, and clinical trial coordination. Am J Respir Crit Care Med 149:818-824

Bochi GV, Torbitz VD, Cargnin LP, Carvalho JA, Gomes P, Moresco RN (2014) An alternative pathway through the Fenton reaction for the formation of advanced oxidation protein products, a new class of inflammatory mediators. Inflammation 37:512-521

Calfee CS, Ware LB, Eisner MD, Parsons PE, Thompson BT, Wickersham N, Matthay MA, NHLBIARDS Network (2008) Plasma receptor for advanced glycation end products and clinical outcomes in acute lung injury. Thorax 63:1083-1089

Chow CW, Abreu MT, Suzuki T, Downey GP (2003) Oxidative stress and acute lung injury. Am J Respir Cell Mol Biol 29:427-431

Gangemi S, Minciullo PL, Magliacane D, Saitta S, Loffredo S, Saija A, Cristani M, Marone G, Triggiani M (2015) Oxidative stress markers are increased in patients with mastocytosis. Allergy 70:436-442

Johnson LN, Koval M (2009) Cross-talk between pulmonary injury, oxidant stress, and gap junctional communication. Antioxid Redox Signal 11:355-367

Koch C, Li L, Figueroa P, Mihaljevic T, Svensson L, Blackstone EH (2009) Transfusion and pulmonary morbidity after cardiac surgery. Ann Thorac Surg 88:1410-1418

Kogan A, Preisman S, Levin S, Raanani E, Sternik L (2014) Adult respiratory distress syndrome following cardiac surgery. J Card Surg 29:41-46

Lentini P, Cal M, Cruz D, Chronopoulos A, Soni S, Nalesso F, Zanella M, Garzotto F, Brendolan A, Piccinni P, Ronco C (2010) The role of advanced oxidation protein products in intensive care unit patients with acute kidney injury. J Crit Care 25:605-609 
Levitt JE, Gould MK, Ware LB, Matthay MA (2009) The pathogenetic and prognostic value of biologic markers in acute lung injury. J Intensive Care Med 24:151-167

Liang X, Chen Y, Zhuang J, Zhang M, Xiong W, Guo H, Jiang F, Hu P, Guo D, Shi W (2012) Advanced oxidation protein products as prognostic biomarkers for recovery from acute kidney injury after coronary artery bypass grafting. Biomarkers 17:507-512

Matata BM, Sosnowski AW, Galinanes M (2000) Off-pump bypass graft operation significantly reduces oxidative stress and inflammation. Ann Thorac Surg 69:785-791

Ng CS, Wan S, Yim AP, Arifi AA (2002) Pulmonary dysfunction after cardiac surgery. Chest 121:1269-1277

Stephens RS, Shah AS, Whitman GJ (2013) Lung injury and acute respiratory distress syndrome after cardiac surgery. Ann Thorac Surg 95:1122-1129

Tuinman PR, Cornet AD, Kuipers MT, Vlaar AP, Schultz MJ, Beishuizen A, Groeneveld AB, Juffermans NP (2013) Soluble receptor for advanced glycation end products as an indicator of pulmonary vascular injury after cardiac surgery. BMC Pulm Med 13:76
Uchida T, Shirasawa M, Ware LB, Kojima K, Hata Y, Makita K, Mednick G, Matthay ZA, Matthay MA (2006) Receptor for advanced glycation end-products is a marker of type I cell injury in acute lung injury. Am J Respir Crit Care Med 173:1008-1015

Vlaar AP, Hofstra JJ, Determann RM, Veelo DP, Paulus F, Kulik W, Korevaar J, de Mol BA, Koopman MM, Porcelijn L, Binnekade JM, Vroom MB, Schultz MJ Juffermans NP (2011) The incidence, risk factors, and outcome of transfusion-related acute lung injury in a cohort of cardiac surgery patients: a prospective nested case-control study. Blood 117:4218-4225

Ward PA (2010) Oxidative stress: acute and progressive lung injury. Ann NY Acad Sci 1203:53-59

Wu P, Xie F, Xue M, Xu X, He S, Lin M, Bai L (2015) Advanced oxidation protein products decrease the expression of calcium transport channels in smal intestinal epithelium via the p44/42 MAPK signaling pathway. Eur J Cell Biol 94:190-203

\section{Submit your manuscript to a SpringerOpen ${ }^{\circ}$ journal and benefit from:}

- Convenient online submission

- Rigorous peer review

- Immediate publication on acceptance

- Open access: articles freely available online

- High visibility within the field

- Retaining the copyright to your article

Submit your next manuscript at $>$ springeropen.com 